\title{
Diaphragm dysfunction, lung aeration loss and weaning-induced pulmonary oedema in difficult-to-wean patients
}

\author{
Martin Dres ${ }^{1,2^{*}} \mathbb{0}$, Emmanuel Rozenberg ${ }^{1}$, Elise Morawiec ${ }^{1}$, Julien Mayaux ${ }^{1}$, Julie Delemazure ${ }^{1}$, \\ Thomas Similowski ${ }^{1,2}$ and Alexandre Demoule ${ }^{1,2}$
}

\begin{abstract}
Background: Diaphragm dysfunction and weaning-induced pulmonary oedema are commonly involved during weaning failure, but their physiological interactions have been poorly reported. Our hypothesis was that diaphragm dysfunction is not particularly associated with weaning-induced pulmonary oedema.

Methods: It was a single-centre and physiological study conducted in patients who had failed a first spontaneous breathing trial and who underwent a second trial. The diaphragm function was evaluated by measuring the tracheal pressure generated in response to a bilateral magnetic phrenic nerves stimulations. Weaning-induced pulmonary oedema was diagnosed in case of failure of the spontaneous breathing trial if patients exhibited signs of plasma concentration or echocardiographic diagnosis of pulmonary artery occlusion pressure elevation.

Results: Fifty-three patients were included and 31/53 (58\%) failed the spontaneous breathing trial, including 24/31 (77\%) patients with weaning-induced pulmonary oedema. Diaphragm dysfunction was present in 33/53 (62\%) patients. Diaphragm dysfunction or weaning-induced pulmonary oedema were present in 26/31 (84\%) of the patients who failed the spontaneous breathing trial. Weaning-induced pulmonary oedema occurred in 20/33 (61\%) patients with a diaphragm dysfunction and in 4/20 (20\%) patients without ( $p=0.005)$.

Conclusion: Weaning-induced pulmonary oedema was three times more frequent in case of diaphragm dysfunction. Even in case of diaphragm dysfunction, physicians might be encouraged to investigate the presence of weaning-induced pulmonary oedema during weaning failure.
\end{abstract}

Keywords: Diaphragm, Pulmonary oedema, Difficult weaning, Lung ultrasound

\section{Introduction}

Weaning-induced pulmonary oedema is a frequent cause of spontaneous breathing trial failure, accounting for up to $60 \%$ of weaning failure in two large observational studies $[1,2]$. Likewise, a strong association has been established between diaphragm dysfunction and spontaneous breathing trial failure $[3,4]$. While the corresponding

\footnotetext{
*Correspondence: martin.dres@aphp.fr

1 Service de Pneumologie, Médecine intensive - Réanimation (Département "R3S"), AP-HP. Sorbonne Université, Hôpital Pitié-Salpêtrière, 75013 Paris, France

Full list of author information is available at the end of the article
}

mechanisms of diaphragm dysfunction and spontaneous breathing trial failure remain incompletely elucidated, they are likely to involve a combination of reduced diaphragm strength [5] and increased lung impedance [6] due to atelectasis secondary to diaphragm weakness [7-9] leading to respiratory load-capacity imbalance. Although diaphragm dysfunction and weaning-induced pulmonary oedema are two important causes of spontaneous breathing trial failure, no study has ever investigated their interaction. On the one hand, diaphragm dysfunction reduces the rise in thoraco-abdominal gradient that could potentially decrease the risk of 
weaning-induced pulmonary oedema $[10,11]$. On the other hand, the respiratory distress that occurs during a failed spontaneous breathing trial involves large negative swings in pleural pressure that influence cardiac performance by increasing the venous return and/or increasing left ventricular afterload [12]. It may result in turn in weaning-induced pulmonary oedema $[13,14]$. In theory, a weak diaphragm should lessen the haemodynamic consequences of spontaneous ventilation during respiratory distress. In addition, diaphragm dysfunction may also cause lung aeration loss that could subsequently lead to weaning failure [15]. We hypothesized that diaphragm dysfunction would be more likely associated with lung aeration loss than with weaning-induced pulmonary oedema. The first objective was to describe the incidence of weaning-induced pulmonary oedema in patients with or without diaphragm dysfunction. Secondary objective was to compare the lung aeration loss according to the presence or absence of diaphragm function.

\section{Methods}

This study complies with the Strengthening the Reporting of Observational Studies in Epidemiology (STROBE) Statement. It was conducted in a medical intensive care unit over a 14-month period between April 2018 and June 2019. The study was approved by the Comite de Protection des Personnes du Sud Ouest et Outre Mer 4 (RCB ID: 2018-A00176-49). Written and oral information about the study was given to patients or their families prior enrolment. Informed consent was obtained from all patients or their relatives.

\section{Study population}

Patients older than 18 years, ventilated via an endotracheal tube for more than $48 \mathrm{~h}$ and who had already failed a first spontaneous breathing trial were eligible. We sought to enrol patients early during the weaning process as soon as the readiness-to-wean criteria (see below) were present. Patients undergoing spontaneous breathing trial during holidays and weekends were not considered for inclusion. Patients had to meet predefined readinessto-wean criteria on daily screening: $\mathrm{SpO}_{2}>90 \%$ or $\mathrm{PaO}_{2} /$ $\mathrm{FiO}_{2} \geq 150 \mathrm{mmHg}$ with a fraction of inspired oxygen $\left(\mathrm{FiO}_{2}\right) \leq 40 \%$ and a positive end-expiratory pressure $\leq 8$ $\mathrm{cmH}_{2} \mathrm{O}$ ] [16]. In our practice, readiness-to-wean criteria are sought for to conduct a spontaneous breathing trial regardless of the presence of readiness to extubate criteria which are the following: cough strength, neurological status and abundance of secretions. Therefore, In case of successful spontaneous breathing trial, extubation may not be considered. Pregnant women, patients with contraindications to magnetic phrenic nerve stimulation (chest tube, cardiac pacemaker or implanted defibrillator, cervical implants), and patients in whom weaning was impossible (pre-existing neuromuscular disorders, cervical cord injury) were not considered for inclusion.

\section{Measurements and data collection}

Upon inclusion, demographic data were prospectively collected: age, gender, comorbidities (chronic hypertension, chronic obstructive pulmonary disease, chronic left ventricle failure), sequential organ failure assessment and simplified acute physiology score, date of intensive care unit admission, date of intubation, main reason for intubation, weight and height upon admission and fluid balance over the last $24 \mathrm{~h}$. In addition, the following clinical variables were prospectively collected before and at the end of the spontaneous breathing trial: systolic and diastolic arterial pressure, heart rate, respiratory rate, $\mathrm{SpO}_{2}$. Arterial blood gases, lactate, plasma protein concentration and haemoglobin were sampled before and at the end of the spontaneous breathing trial. Haemoglobin concentration was measured from the arterial blood sample by the ABL $800 f l e x$ device (Radiometer, Copenhagen, Denmark). The repeatability of the haemoglobin concentration measurements with the ABL 800flex is reported by the manufacturer to be $0.6 \% \pm 1.4 \%$. The plasma protein concentration was measured with the Cobas 7000 c501 device (Roche Diagnostics, Basel, Switzerland). The repeatability of plasma protein concentration measurements with this device is reported by the manufacturer to be $0.6 \% \pm 0.9 \%$.

\section{Diaphragm function evaluation}

Before conducting the spontaneous breathing trial, diaphragm function was assessed in terms of the changes in endotracheal tube pressure induced by bilateral phrenic nerve magnetic stimulation during airway occlusion (Ptr, stim), as described in other reports [3]. Briefly, two figure-of-eight coils connected to a pair of Magstim ${ }^{\circledR} 200$ stimulators (The Magstim Company, Dyfed, UK) were positioned immediately posterior to the sternomastoid muscles at the level of the cricoid cartilage. Bilateral phrenic nerve stimulation was performed while the endotracheal tube was manually occluded and stimulations were delivered at the maximum intensity allowed by the stimulator $(100 \%)$ known to result in supramaximal diaphragm contraction $[3,17]$. The patients were studied in a standardized semi-recumbent position during a brief disconnection of the endotracheal tube from the ventilator. While the endotracheal tube was manually occluded, bilateral anterolateral magnetic stimulation was performed. The absence of active respiratory efforts was verified by checking the absence of drop in airway pressure signal on the laptop's screen. Two operators (MD, ER) were required to achieve both stimulation 
and measurements. After positioning the coils, at least three stimulations were performed at $100 \%$ of maximal output allowed by the stimulator. Stimulations were separated by at least 60-s to avoid superposition. The average of three measures was taken into account for analysis. Ptr,stim was defined as the amplitude of the negative pressure wave following stimulation, taken from baseline to peak. It was measured at the proximal external end of the endotracheal tube, using a linear differential pressure transducer (MP45 $\pm 100 \mathrm{cmH}_{2} \mathrm{O}$, Validyne, Northridge, Calif., USA). The pressure signal was sampled and digitized at $100 \mathrm{~Hz}$ (MP30, Biopac Systems, Santa Barbara, Calif., USA or Powerlab, AD Instruments, Bella Vista, Australia) for subsequent data analysis. Diaphragm function assessment was repeated at the end of the spontaneous breathing trial in the absence of sustained respiratory distress at the end of the spontaneous breathing trial $(\mathrm{SpO} 2<90 \%$, respiratory rate $>30 / \mathrm{min}$ for a least $5 \mathrm{~min}$ ).

\section{Cardiac function evaluation}

Cardiac function was evaluated before conducting the spontaneous breathing trial by transthoracic echocardiography equipped with a cardiac probe (Sparq, Philips) performed by a fully trained and experienced operator (ER) and reviewed off-line by a second operator (MD). The following variables were obtained from the apical four-chamber view: left ventricular ejection fraction (visual estimation), early (E) and late (A) diastolic wave velocities at the mitral valve, tissue Doppler early (e') wave velocity at the lateral mitral valve annulus, the deceleration time of the $E$ wave, cardiac output as estimated by the stroke volume measured using the Doppler method applied at the left ventricular outflow tract, tricuspid annular plane systolic excursion in M-mode, peak systolic velocity at the lateral tricuspid annulus and systolic pulmonary arterial pressure estimated by the tricuspid regurgitation maximal velocity pressure gradient. Finally, colour Doppler mapping was used to detect the presence of significant mitral regurgitation and semiquantitatively assess its severity. The cardiac assessment was completed by a 12-lead electrocardiogram.

\section{Lung aeration}

Lung ultrasound (Philips Sparq) was performed by a trained investigator, who acquired all images of the study. As previously described [15], a 2-4 MHz convex probe was used to scan the whole lung on both sides. The number of B-lines was counted on a rib short-axis scan between two ribs at each intercostal space of the upper and lower parts of the anterior, lateral, and posterior regions of the left and right chest wall (total of 12 areas). For a given region of interest, points were allocated according to the worst ultrasound pattern observed: presence of lung sliding with A lines or fewer than two isolated $\mathrm{B}$ lines $=0$, moderate loss of lung aeration: multiple, well-defined $B$ lines $=1$, severe loss of lung aeration: multiple coalescent $\mathrm{B}$ lines $=2$, lung consolidation $=3$ [15]. Skin was marked to apply the probe at precisely the same area before and after the spontaneous breathing trial. In addition to lung ultrasound, the presence of pleural effusion was also investigated and evaluated, as previously described (small, moderate, large) [18].

\section{Study design}

Patients eligible to the study underwent a spontaneous breathing trial. The spontaneous breathing trial was performed for $30 \mathrm{~min}$ (or less in case of clinical intolerance) with the pressure support level and positive end-expiratory pressure set to zero (so called $0-0$ test), while $\mathrm{FiO}_{2}$ remained unchanged. This spontaneous breathing trial modality is similar to the "T-tube" and reflects equally the work of breathing after extubation [20]. Spontaneous breathing trial failure was defined by the following criteria: respiratory rate $\geq 35$ breaths $/ \mathrm{min}$ or increase $\geq 50 \%$, $\mathrm{SpO}_{2} \leq 90 \%$ or $\mathrm{PaO}_{2} \leq 50 \mathrm{mmHg}$ (with $\mathrm{FiO}_{2} \geq 50 \%$ ), heart rate $\geq 140 \mathrm{bpm}$, de novo supraventricular or ventricular arrhythmia, systolic arterial pressure $>180$ or $<90 \mathrm{mmHg}$, alteration of consciousness, and diaphoresis or any signs of respiratory distress [16]. In the event of spontaneous breathing trial failure, the pre-spontaneous breathing trial settings were resumed.

After obtaining consent and before starting the spontaneous breathing trial, clinical and laboratory variables were collected. Electrocardiogram, echocardiography, lung ultrasound and diaphragm evaluation were performed. The spontaneous breathing trial was then started. At the end of the spontaneous breathing trial or sooner in case of clinical intolerance, electrocardiogram, echocardiography and lung ultrasound were repeated before resuming the initial ventilator settings.

\section{Definitions}

Diaphragm dysfunction was defined by a Ptr,stim below $7 \mathrm{cmH}_{2} \mathrm{O}$ [21-23]. Weaning-induced pulmonary oedema was defined in case of spontaneous breathing trial failure associated with at least one of the following two features:(1) echocardiographic diagnosis of pulmonary artery occlusion pressure elevation (E/A ratio above 0.95 and $\mathrm{E} / \mathrm{e}^{\prime}$ ratio above 8.5 during the spontaneous breathing trial [24]) and/or (2) plasma protein concentration (5\% increase in haemoglobin and/or plasma protein concentration) during the spontaneous breathing trial $[25$, 26]. 


\section{Statistical analysis}

Data were expressed as median (interquartile range) or number (\%). Comparisons between spontaneous breathing trial success and spontaneous breathing trial failure were assessed with a Mann-Whitney $U$ test. Baseline Ptr,stim were compared between patients with spontaneous breathing trial success and patients with spontaneous breathing trial failure associated with or without weaning-induced pulmonary oedema with a Kruskal-Wallis test. Baseline lung ultrasound score was compared between patients with spontaneous breathing trial success and patients with spontaneous breathing trial failure and the presence or absence of diaphragm dysfunction with a Kruskal-Wallis test. The correlation between Ptr,stim and lung ultrasound score was assessed with the non-parametric Spearman correlation. The proportion of patients with weaninginduced pulmonary oedema and with spontaneous breathing trial failure for another reason was compared with a Fisher's exact test. A convenient sample size was defined on the basis of previous similar physiological investigations [25, 27, 28]. Regarding the characteristics of the population included, we assumed a spontaneous breathing trial success/failure rate of $50 \% / 50 \%$ [1, 25 ] and planned to include a minimum of 25 patients per group. We also expected a dropout rate of approximately $10 \%$ due to technical problems, and therefore planned to enrol 55 patients. For all final comparisons, a p value less than or equal to 0.05 was considered to be statistically significant. Analyses were performed using Prism 8.3.0 software (GraphPad Software, USA).

\section{Results}

\section{Study population}

During the study period, 794 patients were admitted to the ICU and 340 received invasive mechanical ventilation. Sixty of these patients were enrolled, seven of whom were subsequently excluded for technical reasons (Fig. 1). Overall, 53 patients were analysed. The main reason for intubation was hypoxemic acute respiratory failure and the median SAPS II score was 61 (49-76). At the time of inclusion, the median duration of mechanical ventilation was 4 (2-9) days (Table 1) and all patients were ventilated with pressure support mode. Overall, left ventricular ejection fraction was $60 \%(50-60)$ and less than $50 \%$ in 5 patients. No significant valvular regurgitation, hypertrophic cardiomyopathy or pericardial effusion was documented. Atrial fibrillation was present in three patients. Thirteen patients had a small-to-moderate pleural effusion.

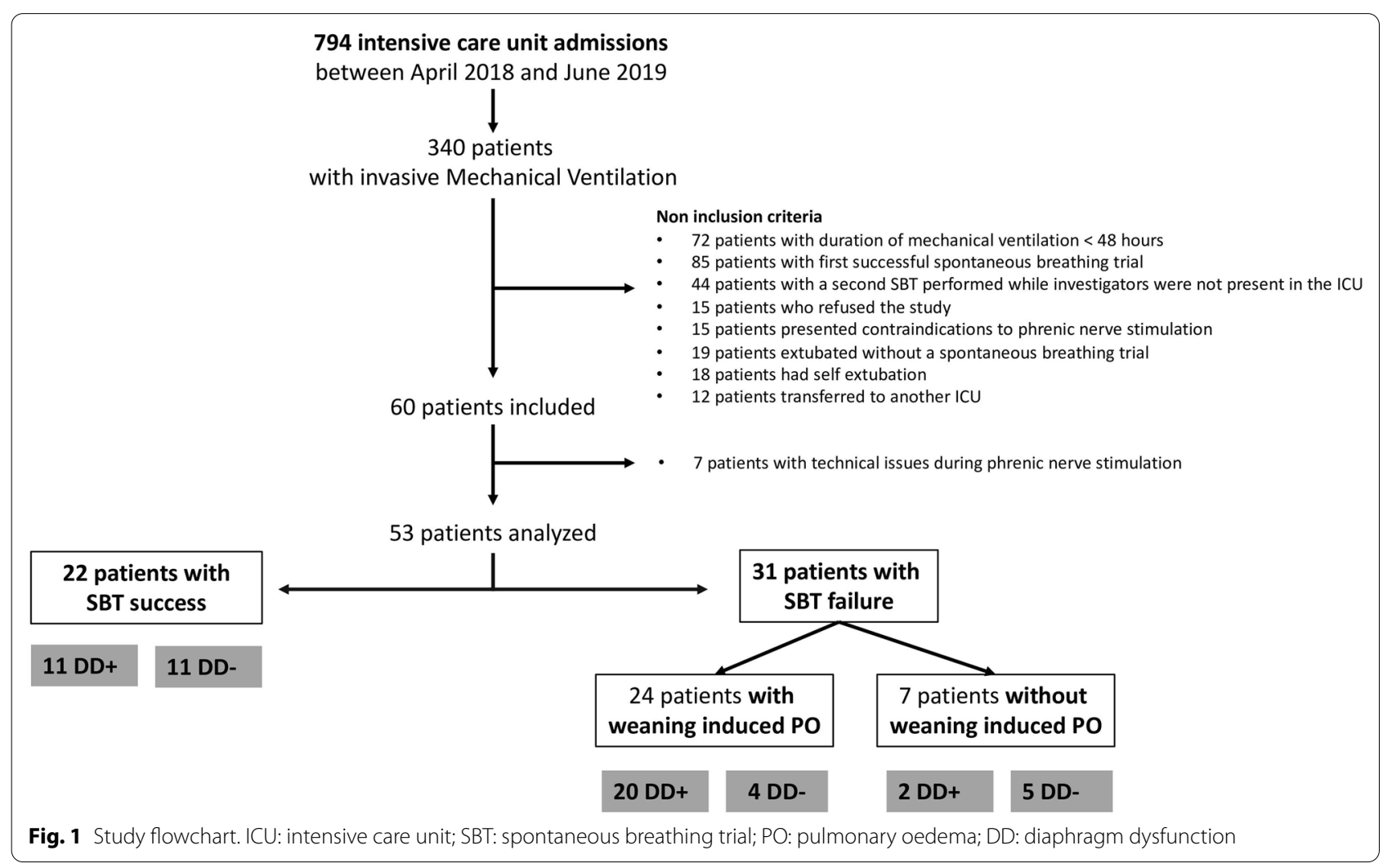


Table 1 Baseline patient characteristics

\begin{tabular}{|c|c|c|c|}
\hline & SBT success $N=22$ & SBT failure $N=31$ & $p$ \\
\hline Age, years & $61(50-71)$ & $63(55-63)$ & 0.638 \\
\hline Female, $n(\%)$ & $10(45)$ & $15(48)$ & 0.999 \\
\hline Body mass index, kg.m ${ }^{-2}$ & $24(21-27)$ & $25(20-30)$ & 0.609 \\
\hline \multicolumn{4}{|l|}{ Pre-existing conditions, $n$ (\%) } \\
\hline Hypertension & $8(36)$ & $10(32)$ & 0.776 \\
\hline Chronic left ventricle failure & $4(18)$ & $8(26)$ & 0.740 \\
\hline COPD & $3(14)$ & $4(13)$ & 0.999 \\
\hline SAPS 2 & $57(47-77)$ & $65(49-76)$ & 0.493 \\
\hline SOFA & $10(6-11)$ & $10(7-12)$ & 0.756 \\
\hline Fluid balance over last 24 h, L & $-0.6(-1.2-0.7)$ & $-0.8(-1.6-0.7)$ & 0.205 \\
\hline Length of ICU stay, days & $5(2-6)$ & $5(2-12)$ & 0.570 \\
\hline Duration of mechanical ventilation, days & $4(2-6)$ & $5(2-11)$ & 0.468 \\
\hline SBT before inclusion, $n$ & $1(1-1)$ & $1(1-1)$ & 0.113 \\
\hline \multicolumn{4}{|l|}{ Main reason for intubation, $n(\%)$} \\
\hline Acute respiratory failure & $13(59)$ & $16(52)$ & 0.779 \\
\hline Coma & $7(32)$ & $12(39)$ & 0.772 \\
\hline Shock & $1(5)$ & $1(3)$ & 0.999 \\
\hline Post-surgery & $1(5)$ & $2(6)$ & 0.999 \\
\hline \multicolumn{4}{|l|}{ Ventilator settings } \\
\hline Pressure support, $\mathrm{cmH}_{2} \mathrm{O}$ & $10(7-10)$ & $12(10-12)$ & $<.001$ \\
\hline PEEP, $\mathrm{cmH}_{2} \mathrm{O}$ & $5(5-6)$ & $6(5-6)$ & 0.076 \\
\hline Expired tidal volume, $\mathrm{ml} \cdot \mathrm{kg}^{-1} \mathrm{IBW}$ & $7(7-9)$ & $7(6-7)$ & 0.053 \\
\hline
\end{tabular}

SBT, spontaneous breathing trial; COPD, chronic obstructive pulmonary disease; SAPS, Simplified Acute Physiology Score; SOFA Sequential Organ Failure Assessment; ICU, intensive care unit; PEEP, positive end-expiratory pressure; IBW, ideal body weight

Diaphragm dysfunction was demonstrated in $33(63 \%)$ patients and median Ptr,stim was $4.7(2.9-8.4) \mathrm{cmH}_{2} \mathrm{O}$.

\section{Reasons for spontaneous breathing trial failure}

Thirty-one (58\%) of the 53 patients enrolled in the study failed the spontaneous breathing trial. Weaning-induced pulmonary oedema was documented in 24 (77\%) of these 31 patients (Figs. 1 and 2). Among the 24 patients with weaning-induced pulmonary oedema, 20/24 had an increase in plasma protein concentration or in haemoglobin or both, 15/24 had an increase in E/A and E/e' ratios and $11 / 24$ had a combination of ultrasound indices and biomarkers.

Among the 31 patients who failed the spontaneous breathing trial, $20(83 \%)$ of the 24 patients with documented weaning-induced pulmonary oedema had diaphragm dysfunction versus $2(29 \%)$ of the 7 patients who failed the spontaneous breathing trial for other reasons $(p=0.012)$ (Fig. 2). Of the seven patients who failed the spontaneous breathing trial for a reason other than weaning-induced pulmonary oedema, two patients failed because of copious secretions, one patient developed central hypoventilation due to Arnold-Chiari malformation, and no precise reason was found in the four remaining patients. Of note, diaphragm dysfunction was present in two of these four patients (Ptr,stim was -2.7 $\mathrm{cmH}_{2} \mathrm{O}$ and $-3.0 \mathrm{cmH}_{2} \mathrm{O}$ ). Overall, diaphragm dysfunction or weaning-induced pulmonary oedema was present in $26 / 31(84 \%)$ of the patients who failed the spontaneous breathing trial.

\section{Impact of diaphragm function on cardiac function during the spontaneous breathing trial}

Weaning-induced pulmonary oedema occurred in 20/33 (61\%) patients with a diaphragm dysfunction and in $4 / 20$ $(20 \%)$ patients without $(p=0.005)$. Clinical variables, echocardiographic measurements and diaphragm function before and at the end of the spontaneous breathing trial are presented in Table 2. Ptr,stim was higher in patients who failed the spontaneous breathing trial for reasons other than weaning-induced pulmonary oedema compared to those who failed the spontaneous breathing trial because of weaning-induced pulmonary oedema (Fig. 3). No correlation was found between Ptr,stim and the changes in protein, haemoglobin, E/A ratio and E/e' ratio during the spontaneous breathing trial. 


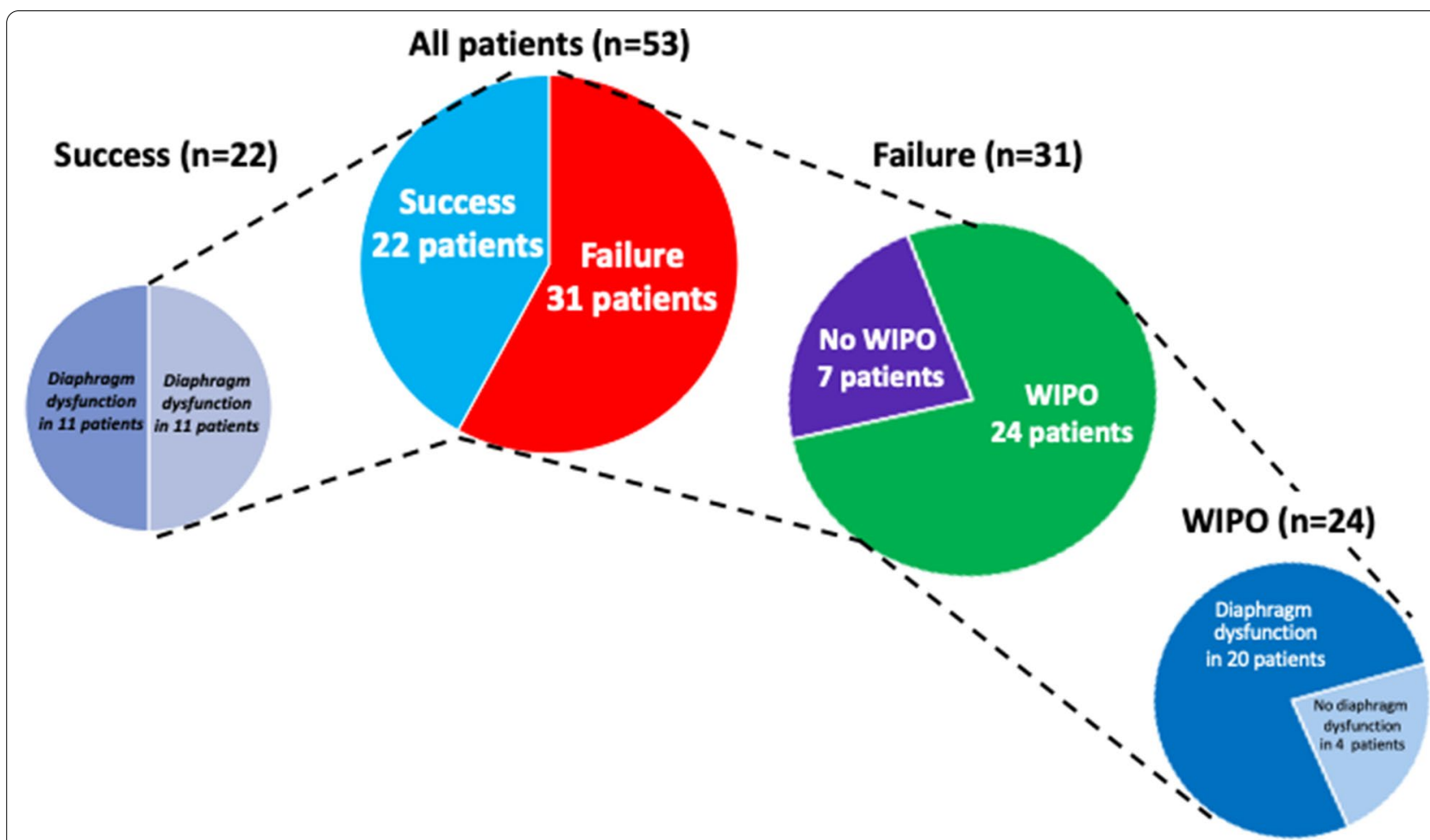

Fig. 2 Outcomes of the spontaneous breathing trial presented with the proportion of patients with diaphragm dysfunction and weaning-induced pulmonary oedema (WIPO)

\section{Impact of diaphragm dysfunction on weaning-induced lung aeration loss}

The lung ultrasound score was significantly higher in patients with diaphragm dysfunction compared to those without diaphragm dysfunction $(21$ (7-33) vs. 6 (0-15), $p=0.003)$. There was a moderate correlation between lung ultrasound score and Ptr,stim $(r=-0.384$ [95\% CI -0.602 to $-0.113, p=0.005])$.

\section{Discussion}

This study shows that, in patients with difficult weaning: (1) diaphragm dysfunction and weaning-induced pulmonary oedema were frequent, both individually and combined and (2) lung ultrasound loss was associated with diaphragm dysfunction and spontaneous breathing trial failure.

\section{Coexistence of weaning-induced pulmonary oedema and diaphragm dysfunction}

Herein, we report a high rate of spontaneous breathing trial failure that is purposely explained by the specific combination of inclusion criteria that we applied: duration of mechanical ventilation longer than $48 \mathrm{~h}$ and failure to the first spontaneous breathing trial. This prevalence is higher than that previously reported (60\%) [1, $2,27]$, but can presumably be explained by the selection of our patients. The definition of weaning-induced pulmonary oedema used in this study could also explain the high prevalence, as we opted to standardize classification of patients based on objective criteria (echocardiography and/or biomarkers) rather than classify patients based on expert consensus $[1,2]$, which may be subject to bias. We also used a challenging weaning trial that is likely to have markedly influenced the intrathoracic pressure [29]. In addition, it is likely that the early spontaneous breathing trial strategy relying on the presence of "readiness-towean criteria" rather on "readiness to extubate criteria" is partially responsible of the high prevalence of weaninginduced pulmonary oedema observed in our population.

Diaphragm dysfunction was present in $63 \%$ of our patients before starting the spontaneous breathing trial and appeared to be particularly severe (median Ptr,stim was $4.7 \mathrm{cmH}_{2} \mathrm{O}$ ). Of note, diaphragm dysfunction was defined by a lower Ptr,stim-threshold $\left(7 \mathrm{cmH}_{2} \mathrm{O}\right)$ than the classical definition of diaphragm dysfunction (11 $\left.\mathrm{cmH}_{2} \mathrm{O}\right)[3,4]$. This definition was based on previous studies demonstrating that a threshold of $11 \mathrm{cmH}_{2} \mathrm{O}$ is likely to over-diagnose diaphragm dysfunction in the ICU setting [21, 23].

Large negative swings in intrathoracic pressure during a spontaneous breathing trial tend to increase the venous return pressure gradient, the central blood volume and 
Table 2 Clinical variables, gas exchange, cardiac function and lung aeration before and at the end of the spontaneous breathing trial

\begin{tabular}{|c|c|c|c|c|c|c|}
\hline & \multicolumn{3}{|l|}{ Before the SBT } & \multicolumn{3}{|l|}{ End of the SBT } \\
\hline & SBT success & SBT failure & $p$ & SBT success & SBT failure & $p$ \\
\hline$n$ & 22 & 31 & & 22 & 31 & \\
\hline \multicolumn{7}{|l|}{ Clinical variables } \\
\hline Systolic ABP, mmHg & $121(110-139)$ & $140(118-151)$ & 0.041 & $130(109-154)$ & $149(128-170)$ & 0.007 \\
\hline Heat rate, $\min ^{-1}$ & $94(77-101)$ & $93(84-104)$ & 0.840 & $97(86-105)$ & $105(96-121)$ & 0.036 \\
\hline Respiratory rate, $\min ^{-1}$ & $19(15-23)$ & $21(18-26)$ & 0.101 & $21(19-31)$ & $28(21-35)$ & 0.030 \\
\hline \multicolumn{7}{|l|}{ Laboratory variables } \\
\hline $\mathrm{pH}$ & $7.42(7.38-7.48)$ & $7.43(7.38-7.45)$ & 0.732 & $7.43(7.40-7.47)$ & $7.38(7.34-7.43)$ & 0.027 \\
\hline $\mathrm{PaO}_{2} / \mathrm{FiO}_{2}$ ratio & $327(237-381)$ & $227(168-280)$ & 0.004 & $253(197-298)$ & $160(107-205)$ & $<0.001$ \\
\hline $\mathrm{PaCO}_{2}, \mathrm{mmHg}$ & $36(30-43)$ & $42(36-49)$ & 0.009 & $39(33-43)$ & $50(38-57)$ & 0.002 \\
\hline Lactate, mmol.. ${ }^{-1}$ & $1.2(0.8-1.6)$ & $1.3(1.0-1.8)$ & 0.254 & $0.9(0.7-1.2)$ & $1.1(1.0-1.5)$ & 0.015 \\
\hline Haemoglobin, g.dL ${ }^{-1}$ & $8.3(7.8-10.4)$ & $9.4(8.4-10.7)$ & 0.227 & $8.6(7.9-10.7)$ & $9.8(8.8-11.5)$ & 0.073 \\
\hline Delta haemoglobin, $\%$ & - & - & & $0(-5-5)$ & $5(1-9)$ & 0.013 \\
\hline Protein, g.. $\mathrm{L}^{-1}$ & $55(48-59)$ & $60(54-65)$ & 0.021 & $53(49-59)$ & $64(58-69)$ & 0.001 \\
\hline Delta protein, \% & - & - & & $4(0-5)$ & $7(2-9)$ & 0.014 \\
\hline \multicolumn{7}{|l|}{ Cardiac function } \\
\hline LEVF, \% & $60(50-60)$ & $60(50-60)$ & 0.319 & $60(50-60)$ & $60(50-60)$ & 0.321 \\
\hline $\mathrm{Cl}, \mathrm{L} \cdot \mathrm{min}^{-1} \cdot \mathrm{m}^{-2}$ & $3.1(2.6-3.9)$ & $3.6(2.9-4.2)$ & 0.264 & $3.6(2.8-4.1)$ & $4.3(3.6-4.9)$ & 0.167 \\
\hline $\mathrm{e}^{\prime}$ wave, $\mathrm{cm} \cdot \mathrm{s}^{-1}$ & $11(9-12)$ & $10(9-12)$ & 0.904 & $10(9-13)$ & $11(9-13)$ & 0.939 \\
\hline E/A ratio & $0.8(0.7-1.1)$ & $1.0(0.8-1.4)$ & 0.177 & $0.9(0.7-0.9)$ & $1.1(0.9-1.3)$ & 0.001 \\
\hline E/e'ratio & $7.1(5.3-8.6)$ & $8.1(6.6-10.5)$ & 0.092 & $7.4(5.3-9.2)$ & $9.3(7.2-1.28)$ & 0.022 \\
\hline$E / e^{\prime}>14, n(\%)$ & $2(10)$ & $1(3)$ & & $1(10)$ & $5(19)$ & \\
\hline DTE, ms & $175(142-210)$ & $172(137-201)$ & 0.967 & $169(142-228)$ & $157(140-200)$ & 0.329 \\
\hline Systolic PAP, mmHg & $23(20-28)$ & $27(20-35)$ & 0.255 & $24(21-36)$ & $30(21-53)$ & 0.165 \\
\hline TAPSE, cm & $2.3(1.9-2.6)$ & $2.1(1.9-2.7)$ & 0.988 & $2.3(2.1-2.7)$ & $2.3(1.9-2.9)$ & 0.839 \\
\hline S wave, $\mathrm{cm} \mathrm{s}^{-1}$ & $15.8(13.7-18.7)$ & $16(14.0-21.1)$ & 0.621 & $17.4(14.1-20.1)$ & $17.0(15.6-20.5)$ & 0.829 \\
\hline \multicolumn{7}{|l|}{ Diaphragm function } \\
\hline Ptr,stim, $\mathrm{cmH}_{2} \mathrm{O}$ & $6.8(3.4-8.8)$ & $4.1(2.7-7.9)$ & 0.098 & $6.0(3.8-8.3)$ & $4.3(2.2-6.9)$ & 0.192 \\
\hline \multicolumn{7}{|l|}{ Lung aeration } \\
\hline Lung consolidation, $n$ & $2(1-4)$ & $4(0-10)$ & 0.026 & $2(0-1)$ & $6(0-10)$ & 0.025 \\
\hline LUS & $10(3-19)$ & $17(4-33)$ & 0.123 & $9(3-20)$ & $20(5-33)$ & 0.060 \\
\hline Posterior LUS & $7(2-12)$ & $10(1-17)$ & 0.377 & $6(2-14)$ & $11(4-17)$ & 0.112 \\
\hline
\end{tabular}

SBT, spontaneous breathing trial; $A B P$, arterial blood pressure; $L E V F$, left ventricular ejection fraction; $\mathrm{Cl}$, cardiac index; $\mathrm{E} / \mathrm{A}$, early (E) over late (A) diastolic wave velocity ratio; E/e', E wave over tissue Doppler early (e') wave velocities at the lateral mitral valve annulus; DTE, deceleration time of the E wave; TAPSE, tricuspid annular plane systolic excursion (TAPSE); PAP, pulmonary artery pressure; LUS, lung ultrasound score

the left ventricular filling pressure (Fig. 4). They also represent an increase in left ventricular afterload. These phenomena can contribute to weaning-induced pulmonary oedema [13]. Of note, diaphragm contractions are powerful drivers of venous return insofar as they simultaneously increase abdominal pressure while decreasing intrathoracic pressure, hence leading to an increased abdomino-thoracic gradient $[10,11]$. As a result, diaphragm dysfunction may limit the occurrence of weaning-induced pulmonary oedema through a reduction in venous return and in inspiratory-related increases in leftventricular afterload. By contrast, diaphragm dysfunction appeared to frequently coexist with weaning-induced pulmonary oedema. One possible explanation for this observation lies in the fact that in the presence of diaphragm dysfunction, extradiaphragmatic inspiratory muscles are recruited to generate large negative pleural pressure swings [30,31]. This should cancel the possibly "positive" haemodynamic effects of diaphragm dysfunction through both an increased venous return and an increased left ventricular afterload [12, 32].

\section{Effect of diaphragm dysfunction on lung aeration loss}

Excessive lung aeration loss at the time of the spontaneous breathing trial is associated with weaning failure $[15,33]$. There are many causes for lung aeration loss, 


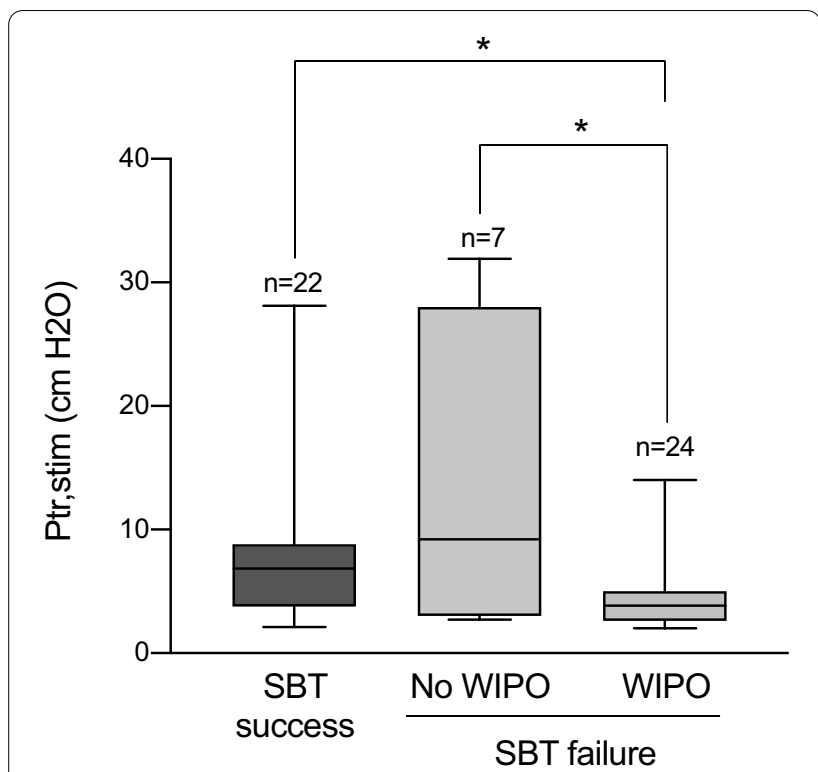

Fig. 3 Diaphragm function as evaluated by measuring the change in tracheal pressure in response to bilateral phrenic nerve stimulation (Ptr,stim) in patients with a successful spontaneous breathing trial (SBT) and those with SBT failure with and without weaning-induced pulmonary oedema (WIPO). Box plots show the median (interquartile)

including alterations in lung compliance/resistance, ventilation/perfusion mismatch, atelectasis and pulmonary oedema. Respiratory muscle weakness has also been suggested to play a role in lung aeration loss during weaning [15], but has never been investigated. Studies performed in the operating room have demonstrated atelectasis induced by diaphragm paralysis [7-9]. Spontaneous ventilation results in preferential distribution of volume to dependent (posterior) lung regions, whereas controlled mechanical ventilation induces preferential ventilation of non-dependent (anterior) lung regions in anaesthetized and paralyzed subjects. A possible explanation for this shift in the ventilation pattern would be the effect of anaesthesia on regional lung compliance and changes in regional chest wall mechanics due to the paralysis of respiratory muscles, especially the diaphragm [9]. Lung ultrasound is an interesting tool in this context since it can show the occurrence of $B$ lines that are mainly generated by weaning-induced pulmonary oedema [27, 28]. Our findings show that patients with diaphragm dysfunction had a significantly higher lung ultrasound score (21 vs. 6), suggesting a greater lung aeration loss compared to patients without diaphragm dysfunction. Importantly, the lung ultrasound score was significantly higher (the lung aeration loss was therefore greater) in patients who failed the spontaneous breathing trial and who had diaphragm dysfunction, whereas patients without diaphragm dysfunction who failed the spontaneous breathing trial had a low lung ultrasound score and consequently preserved lung aeration. Nevertheless, the high frequency of loss of aeration may be partially explain by the strategy of early spontaneous breathing trial performed during the ICU stay, especially when considering the substantial proportion of patients intubated for coma.

\section{Clinical implications}

Our findings may have important clinical implications, since they highlight the fact that the presence of diaphragm dysfunction may not prevent the development of weaning-induced pulmonary oedema. It is noteworthy that a significant proportion of patients (up to $44 \%$ ) can be successfully extubated despite diaphragm dysfunction [4] and a recent study found that diaphragm dysfunction was equally present in patients with extubation success and extubation failure [34]. In addition, a study reported that long-term survival was not influenced by the presence of diaphragm dysfunction at the time of weaning [35].

The main message for clinicians is that, despite the presence of diaphragm dysfunction present before starting a spontaneous breathing trial, it is still important to investigate other possible causes of spontaneous breathing trial failure, including weaning-induced pulmonary oedema, which is the commonest and easiest to manage cause. Importantly, in case of weaning-induced pulmonary oedema associated with diaphragm dysfunction, treatment of weaning-induced pulmonary oedema may facilitate weaning by improving the respiratory load/ capacity balance. Since our population was selected early during the weaning phase at the time where patients were deemed ready to undergo a spontaneous breathing trial but not extubation, these clinical implications warrant further studies. Another important result of our study is the association between diaphragm dysfunction and lung atelectasis. This may be a useful finding, as the lung ultrasound score could be used as an endpoint of diaphragm function improvement in the context of future clinical trials.

\section{Limitations}

This study has several limitations. First, neither intrathoracic pressure nor abdominal pressure was monitored during the spontaneous breathing trial. Consequently, no data can be provided concerning the level of intrathoracic pressure generated by respiratory muscles. Measuring the transdiaphragmatic pressure that is the result of the contraction of the diaphragm would have allowed to better elucidate the influence of the diaphragm function on cardiac function during weaning. Second, the diagnosis of weaning-induced pulmonary oedema was 


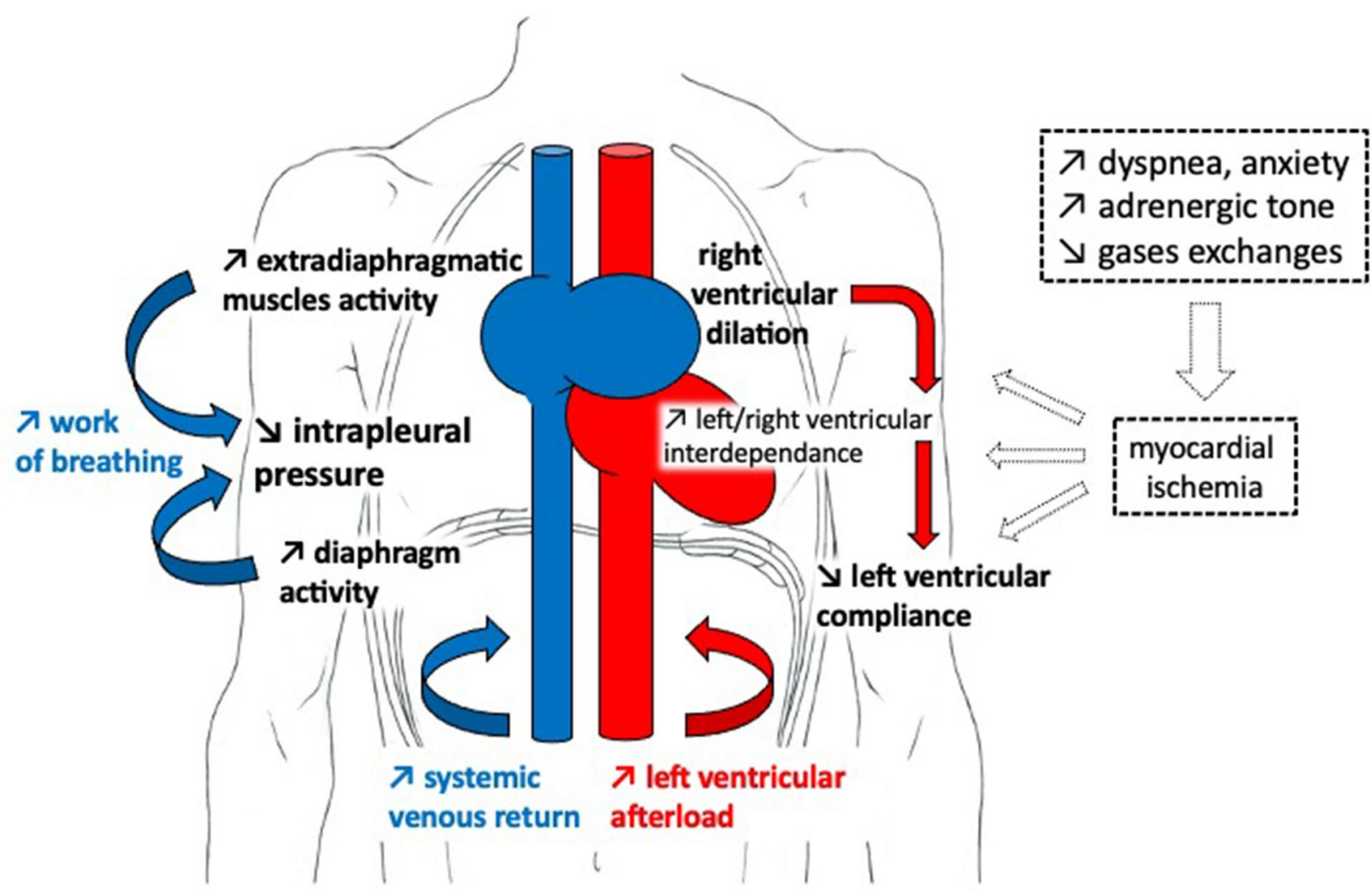

\section{$\lambda$ Left ventricular preload \\ $\lambda$ left ventricular filling pressure}

Fig. 4 Main pathophysiological mechanisms involved in the occurrence of weaning-induced pulmonary oedema. The decrease is intrathoracic pressure is mediated through the contraction of the diaphragm and extradiaphragmatic respiratory muscles. It may lead to an increase in systemic venous return and cardiac preload. The decrease in intrathoracic pressure is also responsible for an increase in left ventricular afterload. The increase in right ventricular preload could induce a right ventricular dilation that can lead to ventricles interdependence and impaired left ventricular compliance potentially exacerbated by myocardial ischaemia

based on laboratory and echocardiographic criteria and not based on the reference method, i.e. measurement of pulmonary artery occlusion pressure elevation. However, current practices are based on alternatives to pulmonary artery catheter to diagnose weaning-induced pulmonary oedema, which is now considered to be an invasive technique at the time of weaning [13]. Third, the fluid balance was only obtained during the last $24 \mathrm{~h}$ preceding the spontaneous breathing trial. Fourth, the occurrence of mitral regurgitation was evaluated at baseline, but not at the end of the spontaneous breathing trial.

\section{Conclusion}

Diaphragm dysfunction and weaning-induced pulmonary oedema are frequently associated in difficult-towean patients and diaphragm dysfunction is associated with lung aeration loss. This study suggests that the presence of diaphragm dysfunction in difficult-to-wean patients may encourage physicians to investigate the presence of weaning-induced pulmonary oedema. It may help to accelerate the weaning process by improving the respiratory load/capacity balance, particularly in case of diaphragm dysfunction.

\section{Acknowledgements}

The authors thank the medical and paramedical caregivers and the patients and their family for their help in conducting the study.

\section{Authors' contributions}

$M D$ designed and coordinated the study. MD, ER, JD, JM, EM were responsible for patient screening, enrolment and follow-up. MD, TS, ER and AD analysed the data. MD, ER, AD and TS wrote the manuscript. All authors had full access to all of the study data, contributed to drafting the manuscript or critically revised it for important intellectual content, approved the final version of the manuscript, and took responsibility for the integrity of the data and the accuracy of the data analysis. All authors read and approved the final manuscript. 


\section{Funding}

Supported by a grant from the French Intensive Care Society and the French Society of Pulmonology.

\section{Availability of data and materials}

The datasets used and/or analysed during the current study are available from the corresponding author on reasonable request.

\section{Declarations}

\section{Ethics approval and consent to participate}

The study was approved by the Comité de Protection des Personnes du Sud Ouest et Outre Mer 4 (RCB ID: 2018-A00176-49).

\section{Consent for publication}

Written and oral information about the study was given to patients or their families prior to enrolment. Informed consent was obtained from all patients or their relatives.

\section{Competing interests}

Martin Dres received fees from Lungpacer (expertise, lectures). Thomas Similowski reports personal fees from AstraZeneca, Boehringer Ingelheim France, GSK, Novartis, Lungpacer Inc., TEVA, Chiesi, and Invacare. In addition, Dr. Similowski has a patent titled "brain-ventilator interface" licensed to Air Liquide Medical Systems and MyBrainTechnology, a patent for a "protection device for intubation" pending, and a patent for a "non-contact thoracic movement imaging system» pending. Alexandre Demoule reports personal fees from Medtronic, grants, personal fees and non-financial support from Philips, personal fees from Baxter, personal fees from Hamilton, personal fees and non-financial support from Fisher \& Paykel, grants from French Ministry of Health, personal fees from Getinge, grants and personal fees from Respinor, grants and non-financial support from Lungpacer. Other authors report no conflict of interest.

\section{Author details}

${ }^{1}$ Service de Pneumologie, Médecine intensive - Réanimation (Département "R3S"), AP-HP. Sorbonne Université, Hôpital Pitié-Salpêtrière, 75013 Paris, France. ${ }^{2}$ Sorbonne Université, INSERM, UMRS1158 Neurophysiologie Respiratoire Expérimentale et Clinique, Paris, France.

Received: 6 March 2021 Accepted: 9 June 2021

Published online: 28 June 2021

\section{References}

1. Liu J, Shen F, Teboul J-L, Anguel N, Beurton A, Bezaz N, et al. Cardiac dysfunction induced by weaning from mechanical ventilation: incidence, risk factors, and effects of fluid removal. Crit Care. 2016;20:369.

2. Bedet A, Tomberli F, Prat G, Bailly P, Kouatchet A, Mortaza S, et al. Myocardial ischemia during ventilator weaning: a prospective multicenter cohort study. Crit Care. 2019;23:321.

3. Dres M, Dubé B-P, Mayaux J, Delemazure J, Reuter D, Brochard L, et al. Coexistence and impact of limb muscle and diaphragm weakness at time of liberation from mechanical ventilation in medical intensive care unit patients. Am J Respir Crit Care Med. 2017;195:57-66.

4. Jung B, Moury PH, Mahul M, de Jong A, Galia F, Prades A, et al. Diaphragmatic dysfunction in patients with ICU-acquired weakness and its impact on extubation failure. Intensive Care Med. 2016;42:853-61.

5. Jaber S, Petrof BJ, Jung B, Chanques G, Berthet J-P, Rabuel C, et al. Rapidly progressive diaphragmatic weakness and injury during mechanical ventilation in humans. Am J Respir Crit Care Med. 2011;183:364-71.

6. Jubran A, Tobin MJ. Passive mechanics of lung and chest wall in patients who failed or succeeded in trials of weaning. Am J Respir Crit Care Med. 1997;155:916-21.

7. Hedenstierna G, Tokics L, Lundquist H, Andersson T, Strandberg A, Brismar B. Phrenic nerve stimulation during halothane anesthesia Effects of atelectasis. Anesthesiology. 1994;80:751-60.

8. Reber A, Nylund U, Hedenstierna G. Position and shape of the diaphragm: implications for atelectasis formation. Anaesthesia. 1998;53:1054-61.
9. Froese $A B$, Bryan $A C$. Effects of anesthesia and paralysis on diaphragmatic mechanics in man. Anesthesiology. 1974;41:242-55.

10. Aliverti A, Uva B, Laviola M, Bovio D, Lo Mauro A, Tarperi C, et al. Concomitant ventilatory and circulatory functions of the diaphragm and abdominal muscles. J Appl Physiol. 2010;109:1432-40.

11. Aliverti A, Bovio D, Fullin I, Dellacà RL, Lo Mauro A, Pedotti A, et al. The abdominal circulatory pump. PLoS ONE. 2009;4:e5550.

12. Buda AJ, Pinsky MR, Ingels NB, Daughters GT, Stinson EB, Alderman EL. Effect of intrathoracic pressure on left ventricular performance. N Engl J Med. 1979;301:453-9.

13. Teboul J-L. Weaning-induced cardiac dysfunction: where are we today? Intensive Care Med. 2014;40:1069-79.

14. Routsi C, Stanopoulos I, Kokkoris S, Sideris A, Zakynthinos S. Weaning failure of cardiovascular origin: how to suspect, detect and treat-a review of the literature. Ann Intensive Care. 2019;9:6.

15. Soummer A, Perbet S, Brisson H, Arbelot C, Constantin J-M, Lu Q, et al. Ultrasound assessment of lung aeration loss during a successful weaning trial predicts postextubation distress. Crit Care Med. 2012;40:2064-72.

16. Boles J-M, Bion J, Connors A, Herridge M, Marsh B, Melot C, et al. Weaning from mechanical ventilation. Eur Respir J. 2007;29:1033-56.

17. Polkey MI, Kyroussis D, Hamnegard CH, Mills GH, Green M, Moxham J. Diaphragm strength in chronic obstructive pulmonary disease. Am J Respir Crit Care Med. 1996;154:1310-7.

18. Dres M, Roux D, Pham T, Beurton A, Ricard J-D, Fartoukh M, et al. Prevalence and impact on weaning of pleural effusion at the time of liberation from mechanical ventilation: a multicenter prospective observational study. Anesthesiology. 2017;126:1107-15.

19. Sklar MC, Burns K, Rittayamai N, Lanys A, Rauseo M, Chen L, et al. Effort to breathe with various spontaneous breathing trial techniques. A physiologic meta-analysis. Am J Respir Crit Care Med. 2017;195:1477-85.

20. Mahul M, Jung B, Galia F, Molinari N, de Jong A, Coisel Y, Vaschetto R, Matecki S, Chanques G, Brochard L, Jaber S. Spontaneous breathing trial and post-extubation work of breathing in morbidly obese critically ill patients. Crit Care. 2016;20(1):346.

21. Dres M, Goligher EC, Dubé B-P, Morawiec E, Dangers L, Reuter D, et al. Diaphragm function and weaning from mechanical ventilation: an ultrasound and phrenic nerve stimulation clinical study. Ann Intensive Care. 2018:8:53.

22. Dres M, Jung B, Molinari N, Manna F, Dubé B-P, Chanques G, et al. Respective contribution of intensive care unit-acquired limb muscle and severe diaphragm weakness on weaning outcome and mortality: a post hoc analysis of two cohorts. Crit Care. 2019;23:370.

23. Qing Q, Liang M, Sun Q, Xie B, Yang C, Liang W, et al. Using twitch tracheal airway pressure, negative inhale forced pressure, and Medical Research Council score to guide weaning from mechanical ventilation. J Thorac Dis. 2018;10:4424-32.

24. Lamia B, Maizel J, Ochagavia A, Chemla D, Osman D, Richard C, et al. Echocardiographic diagnosis of pulmonary artery occlusion pressure elevation during weaning from mechanical ventilation. Crit Care Med. 2009;37:1696-701.

25. Dres M, Teboul J-L, Anguel N, Guerin L, Richard C, Monnet X. Extravascular lung water, B-type natriuretic peptide, and blood volume contraction enable diagnosis of weaning-induced pulmonary edema. Crit Care Med. 2014;42:1882-9.

26. Anguel N, Monnet X, Osman D, Castelain V, Richard C, Teboul J-L. Increase in plasma protein concentration for diagnosing weaning-induced pulmonary oedema. Intensive Care Med. 2008:34:1231-8.

27. Ferré $A$, Guillot M, Lichtenstein D, Mezière G, Richard C, Teboul J-L, et al. Lung ultrasound allows the diagnosis of weaning-induced pulmonary oedema. Intensive Care Med. 2019;45:601-8.

28. Bouhemad B, Mojoli F, Nowobilski N, Hussain A, Rouquette I, Guinot P-G, et al. Use of combined cardiac and lung ultrasound to predict weaning failure in elderly, high-risk cardiac patients: a pilot study. Intensive Care Med. 2020:46:475-84.

29. Guérin C, Terzi N, Mezidi M, Baboi L, Chebib N, Yonis H, et al. Low-pressure support vs automatic tube compensation during spontaneous breathing trial for weaning. Ann Intensive Care. 2019;9:137.

30. Hart N, Nickol AH, Cramer D, Ward SP, Lofaso F, Pride NB, et al. Effect of severe isolated unilateral and bilateral diaphragm weakness on exercise performance. Am J Respir Crit Care Med. 2002;165:1265-70. 
31. Dres M, Dubé B-P, Goligher E, Vorona S, Demiri S, Morawiec E, et al. Usefulness of parasternal intercostal muscle ultrasound during weaning from mechanical ventilation. Anesthesiology. 2020;132:1114-25.

32. Lemaire F, Teboul JL, Cinotti L, Giotto G, Abrouk F, Steg G, et al. Acute left ventricular dysfunction during unsuccessful weaning from mechanical ventilation. Anesthesiology. 1988;69:171-9.

33. Longhini F, Maugeri J, Andreoni C, Ronco C, Bruni A, Garofalo E, et al. Electrical impedance tomography during spontaneous breathing trials and after extubation in critically ill patients at high risk for extubation failure: a multicenter observational study. Ann Intensive Care. 2019;9:88.

34. Vivier E, Muller M, Putegnat J-B, Steyer J, Barrau S, Boissier F, et al. Inability of diaphragm ultrasound to predict extubation failure: a multicenter study. Chest. 2019;155:1131-9.
35. Saccheri C, Morawiec E, Delemazure J, Mayaux J, Dubé B-P, Similowski T, et al. ICU-acquired weakness, diaphragm dysfunction and long-term outcomes of critically ill patients. Ann Intensive Care. 2020;10:1.

\section{Publisher's Note}

Springer Nature remains neutral with regard to jurisdictional claims in published maps and institutional affiliations.

\section{Submit your manuscript to a SpringerOpen ${ }^{\circ}$ journal and benefit from:}

- Convenient online submission

- Rigorous peer review

- Open access: articles freely available online

- High visibility within the field

- Retaining the copyright to your article

Submit your next manuscript at $\boldsymbol{\nabla}$ springeropen.com 